\title{
Personality traits of wheelchair basketball players
}

\section{Wit Jędrzejewski Aleksander Stuła Olga Komarnicka-Jędrzejewska}

\begin{abstract}
Wheelchair basketball is a type of team sport. The rules are similar to those of traditional basketball with the small difference of the game being played in a sitting position on a wheelchair. This article describes the research concerned with personality traits displayed by the wheelchair basketball players of the highest world level. Answers to questions that were based on a psychological method of assessing one's personality were used to write the article. The authors try to determine which personality traits contribute to success in sport, whether leading world players have similar personality traits, and whether in an internationally successful team the same characteristics help or impede the game. As there is only a limited amount of literature on the subject of wheelchair basketball, and even less on the subject of sport psychology concerned with disabled players, this research is based on actual need for information. The results can be used as the basis for posing following question about disabled team sports: whether the models of functioning in a group are different for people with disabilities and without them. Additionally it is important to analyze whether personality traits of athletic people with disabilities differ from personality traits of people without disabilities. The research subjects consist of a highly selective, unique group of people of the highest, world athletic level.
\end{abstract}

Key words: Wheelchair basketball, personality traits, "Big Five", team sports

\section{Introduction}

Team sports, wheelchair basketball included, are among disciplines characterized by open habits. That means that a player is in a dynamic state throughout, his movements are acyclical and done simultaneously (Naglak 2005). Therefor a player on the court performs various actions with and without a ball that require complete mental engagement. These actions only resemble each other, but are never repeated completely. A player has to perform every movement in a conscious, purposeful manner and at will.

Every movement engages the central nervous system, not only through muscle work, but also through concentration, fast decision making, attention divisibility, observation and fast drawing of conclusion (Chmura 1994).

Psychomotor agility is also seen as varied abilities and skills such as: movement control, movement coordination, adaptation of movement depending on needs, ability to visualize movement and imagine experiencing movement, motor memory capacity (Martin 1998). Every person has the innate psychological and motor potential, working learning processes and ability to analyze and make decisions. Therefore the learning, decision making and executive processes are integrated with the motor characteristics, and should not be analyzed separately (Chmura 1994).

Traditionally sport games are defined as the sport disciplines in which opposing subjects with opposing interests take part, the success of one team is equal with the failure of the other one. During competition they exhibit their dexterity in controlling a specific item (tool), e.g. a ball, which is pivotal to the game and determines actions and reactions of the players: precise movement, fast change from one highly specialized movement to another, as well as choice of a movement based on what is happening during the game (Ważny 1981).

Team sports have construction conducive to shaping player's psychophysical traits as the rules are clear and identical for every player, all the competing players have equal chances which allows for the crucial element of competition. The substantial expansion of the physicality through the ongoing trainings does not minimize the importance of the psychological aspect. Participation in sports requires intensive training that allows the participants to compete, verify their abilities, discipline and perseverance. There is a type of imposed restrictions to remove actions that are not necessary to reach the goal of the winning score (Krawczyk 1978).

It is crucial to learn, at least on a basic level, how to operate the technical aspect of the game to execute the strategic actions. When ease in controlling a ball allows for scoring points, the satisfaction felt by the player increases. Furthering this point, there is a connection between the satisfaction gained through participation in a game and the number of conditions that have to be met including the rules of the game, as they do increase proportionally to each other. The rules of the game are clear and open everyone, they are not unpredictable. It is known that the game ends in a victory, failure or tie. Although it is impossible to predict who will win and who will lose. The result is always determined by all of the players and is measured by the number of scored points. The essence of the game is the fact that both teams have equal chances.

Currently it is increasingly popular in extreme sports to see the qualities associated with fun being 
substituted with qualities associated with work. It is connected to the role that sport plays in people's lives, the amount of time that is needed to get ready for work. The ubiquitous professionalization and commercialization of sport (including disabled sport) changes the game from fun to work (Krawczyk 1978).

Every sport makes one try to play in a more efficient way. To accomplish that it is necessary for a process to take place that includes making right decisions and taking right actions. A situation during a game stimulates one and provokes them to a specific action and that action changes the situation on the court. Regulation of stimulation is effective when stimulation correlates with the emotional reactiveness and the possibility of reworking stimulation. When stimulation is kept up on an optimal level it allows for the highest agility possible. The problem has to be found, analyzed, ways to solve it need to be found, results assessed. All of these processes have to take place in the shortest time. That allows for the most efficient actions.

Qualities like repeatability, wide array of possible actions, spontaneity, empathy, ability to create situations, have substantial influence on physical agility. Sport is connected to long lasting and regular activity, and actions during the games are varied and freeform. Specific sports differ from each other when it comes to stimulation, which justifies the search for influence of the psychological elements like personality traits and disposition.

\section{Research objective}

The goal of this paper is to assess the characteristics of the six best wheelchair basketball players of the Polish national team.

\section{Materials and methods}

The research has been conducted on a group of six players of the Polish national team before the European Tournament in Adana (Turkey) in 2009. Polish national team took home fourth prize (the best result in team's history). Additionally they secured a spot and advanced to the World Championship in 2010, where the team placed six. As the result they came in fourth during the European Championship in Nazareth (Israel) in 2011 and were $8^{\text {th }}$ during the Paralympic Games.

The Polish national team consists of world leading players that specialize in wheelchair basketball.

\section{II.1 Methods}

For the purpose of this research the NEO-FFI questionnaire has been used. The questionnaire measures the five basic factors of personality considered to be the most universal: openness to experience, conscientiousness, extraversion, agreeableness, and neuroticism. The five-factor personality model (the socalled „big five") is considered to be the most popular approach for describing human personality (in characteristics) in modern psychology (Szarota 1995). The concept has extensive practical value in the assessment of personality traits.

The basis of the "big five" consists of a hypothesis according to which the most important individual differences are coded in the language. That is why the analysis of the language that we use to describe ourselves and others may be used to identify the personality traits that are distinguished as the "big five".

Research presented in this paper has been based on the "big five" model by Costa and McCrae(1992), that was created with the use of standardized personality questionnaires.

The paper presents a summary of the personality traits distinguished by Costa and Mccrae as the "big five". People characterized by a high level of neuroticism tend to be emotionally unbalanced, intensive and experience mood swings, they lack composure when faced with danger and have limited abilities to cope with stress.

People characterized by a high level of extraversion tend to be in a good mood, intensively engage in social activities, are sociable, talkative and optimistic, have fun, seek intensive experiences, have a lot of stamina.

High level of openness to experience results in curiosity about the world, desire for new experiences, independence, creativeness, unconventionality, interest in culture and art, aesthetic sensitivity and tolerance.

Agreeableness presents itself through positive attitude towards people, interpersonal orientation, empathy, cooperative attitude, tendency to help other people.

People characterized by a high level of conscientiousness are organized, punctual, dependable, compulsive, exhibit perseverance when it comes to achieving their goals, need to achieve high social status, they are workaholics and perfectionists. 


\section{III.1 A.M. (no 6) 1.5 points}

\section{Results}

The conducted research indicates that the person received high scores in the following categories: conscientiousness, agreeableness and extraversion. The raw scores were: CON-36, EX-32, AGR-29. The standard scores were: CON-8, EX-6, AGR-6. On the scale of openness OP-18 and the standard score of OP-2, the subject received a low score which indicates weak qualities despite moderate score (17-19) in the confidence interval. People characterized by a low level of openness tend to be conservative when it comes to their value system, but the level of openness itself may be modified by the environment and situations in which the subject participates. The subject displayed an average level of neuroticism. The analysis of the above mentioned research indicates that the subject displays characteristics consistent with consciousness, agreeableness and extraversion therefore is a person who is punctual, dependable, optimistic, tends to have fun, likes to keep company and is in a good mood. Low level of agreeableness may be connected to the development of an independent personality.

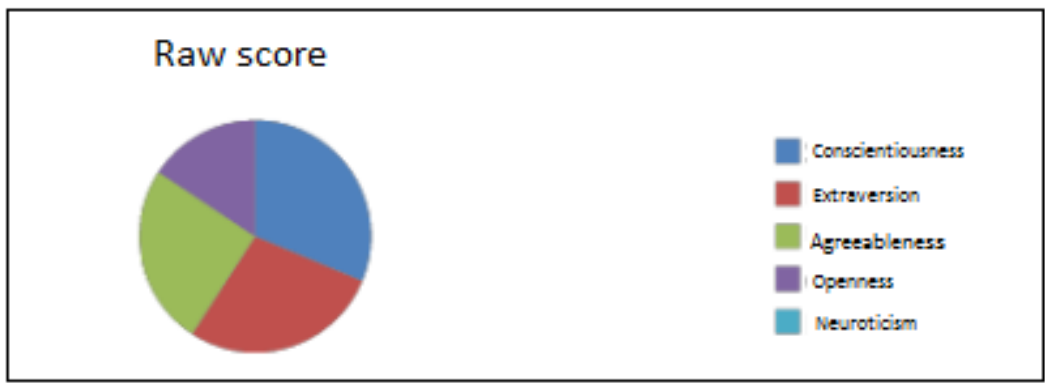

Fig. 1 Raw score A.M.

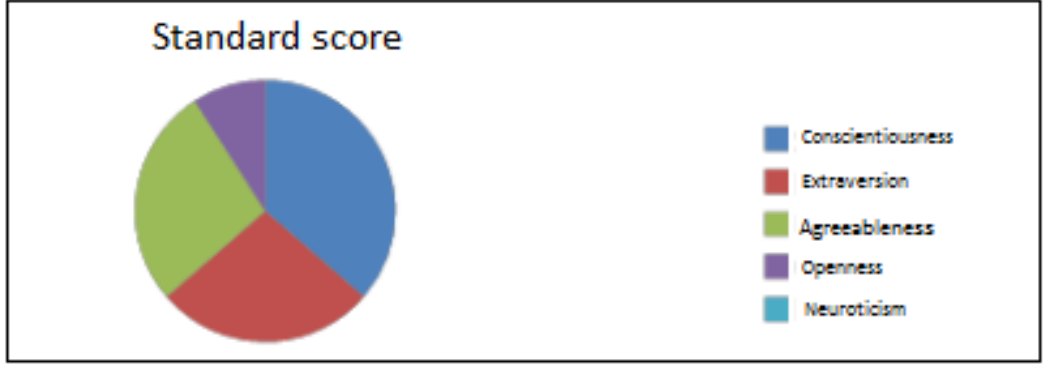

Fig. 2 Standard score A.M.

\section{III.2K.P (no 7) 1.0 points}

The conducted research indicates that the person received high scores in the following categories: extraversion and agreeableness. The raw scores were: CON-38, EX-36. The standard scores were: CON-8, EX8. On the scales of openness and agreeableness the subject got a moderate result which excludes these characteristics as personality traits of the subject. Low score in neuroticism, the raw score: NEU-9, the standard score: NEU-2 which means that the subject does not experience negative emotions such as anger, exasperation, sense of guilt often. In the analysis of the aforementioned research it is evident that the subject exhibits personality traits such as: extraversion and conscientiousness which means that the person is punctual, dependable, optimistic, tends to have fun, likes to keep company and is in a good mood.

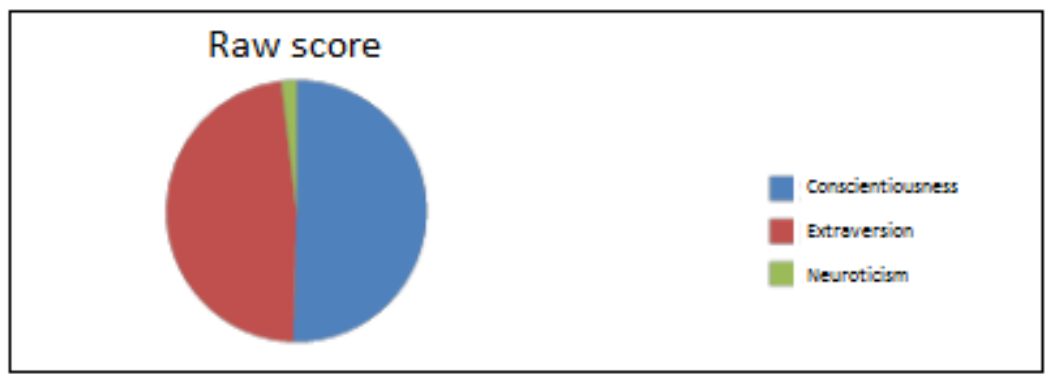

Fig. 3 Raw score K.P. 


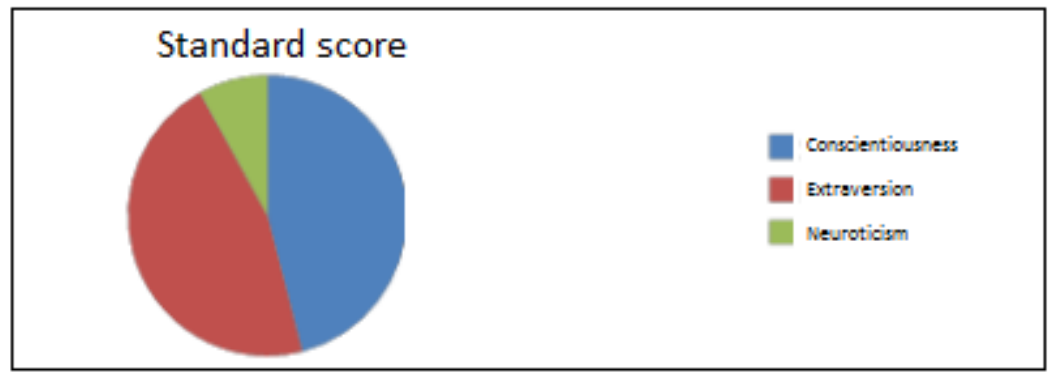

Fig. 4 Standard score K.P.

\section{III.3J.C (no 15) 3.0 points}

The conducted research indicates that the person received a high score in extraversion. The raw score: EX-41. The standard score: EX-10. On the scales of agreeableness and conscientiousness the subject received high scores. The raw scores: AGR-36, CON-38. The standard scores: AGR-8, CON-8. The lowest scores were received on the scales of openness and neuroticism. The raw scores: OP-11, NEU-7, the standard scores: OP-1, NEU-2 which means that the subject does not experience negative emotions such as anger or guilt often. People characterized by a low level of openness tend to be conservative when it comes to their value system, but the level of openness itself may be modified by the environment and the situations in which the subject participates. The analysis of the aforementioned research indicates that the subject presents qualities consistent with extraversion, agreeableness and conscientiousness like punctuality, dependability in a workplace, optimism, tendency to have fun, sociability, good mood and connected to altruism, positive attitude towards other people and high level of trust towards others. It is important not to look at this quality without deeper understanding. As in the case of openness to experience, the situational context seems to be important.

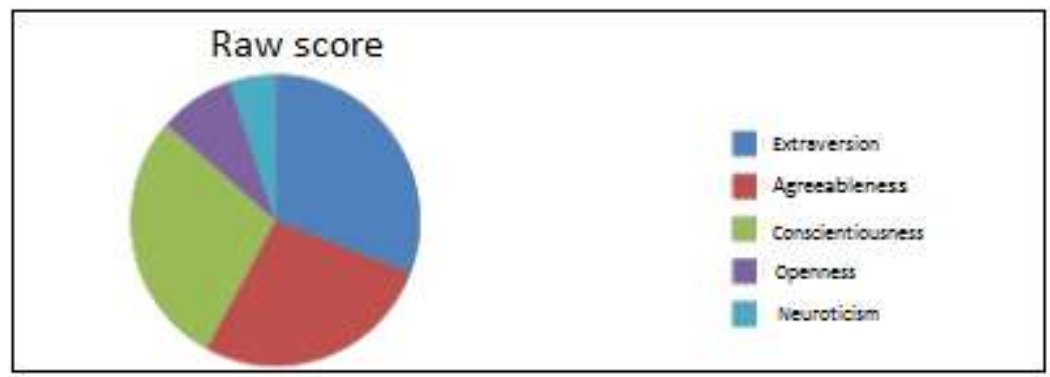

Fig. 5 Raw score J.C.

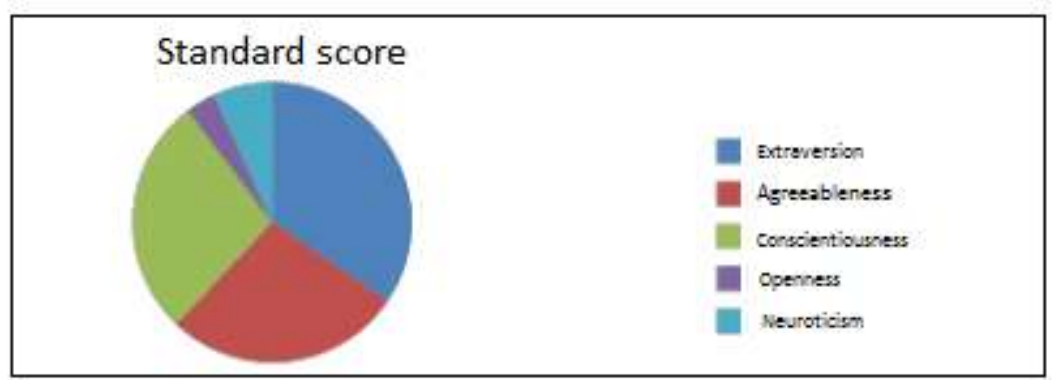

Fig. 6 Standard score J.C.

\section{III.4M.B (no 12) 1.0 points}

The conducted research indicates that the subject received high scores on the extraversion scale. The raw score was: EX-35, the standard score was EX-8. On the scales of openness and conscientiousness the subject received medium-high scores. The raw scores were: OP-28, CON-34, the standard scores were: OP-6, CON-6. The subject received the lowest scores on the scales of agreeableness and neuroticism. The raw scores: AGR-25, NEU-9, the standard scores: AGR-4, NEU-3 which means that the subject does not experience negative emotions such as anger, exasperation or sense of guilt often. Low level of agreeableness is characteristic of the people who are critical, distanced and sceptical. Their individualism and need to be different mean that they almost always have an opinion on a given subject. They also think that every person has a right to have their own opinion and that a healthy dose of competition is crucial to every endeavour. The 
analysis of the aforementioned research shows that the subject presents character traits connected to extraversion, conscientiousness and openness, the subject is someone who is optimistic and in a good mood, has fun, prefers to function in social situations, has a tendency to look for new life experiences, but also to interpret them with a positive spin. People who exhibit a high level of openness are curious of the world, open to explore, have a wide array of interest, and also (according to the authors) have lives richer with experiences. It is noteworthy that this aspect is clearly connected to intellectual qualities; ability to learn, perceive and have a specific way of thinking. Additionally the subject may be inclined to participate in varied activities, achieve goals, and be engaged in human interactions.

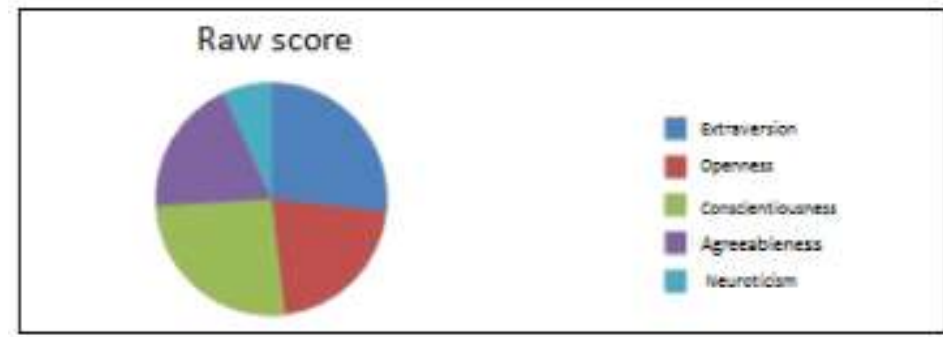

Fig. 7 Raw score M.B.

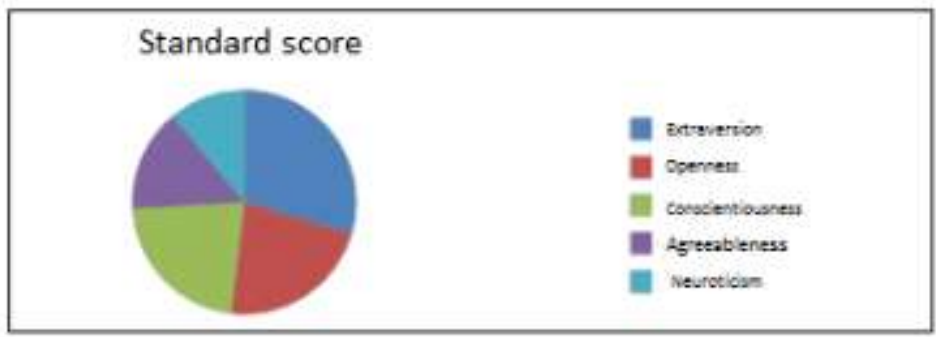

Fig. 8 Standard score M.B.

\section{III.5P.L(no 11) 4.5 points}

The conducted research indicates that the subject presented high scores on the scales of extraversion, conscientiousness, openness. The raw scores: CON-37, EX-30, OP-30. The standard score: CON-7, EX-7, OP7. On the neuroticism scale the subject received a medium score which exclude this trait as an important one. The subject received a low score on the agreeableness scale, the raw score: AGR-25, the standard score: AGR-4. Low level of agreeableness is characteristic of the people who are critical, distanced and sceptical. Their individualism and need to be different mean that they almost always have an opinion on a given subject. They also think that every person has a right to have their own opinion and that a healthy dose of competition is crucial to every endeavour. The analysis of the aforementioned research shows that the subject presents character traits connected to extraversion, conscientiousness and openness, the subject is someone who is predominantly punctual and dependable in a workplace, tends to have fun, prefers to keep company and is optimistic and in a good mood. People who exhibit a high level of openness are curious of the world, open to explore, have a wide array of interest, and also (according to the authors) have lives richer with experiences. It is noteworthy that this aspect is clearly connected to intellectual qualities; ability to learn, perceive and have a specific way of thinking.

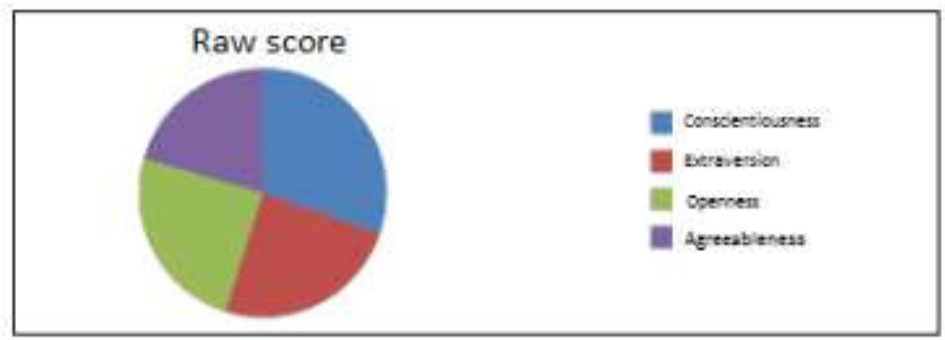

Fig. 9 Standard score P.Ł. 


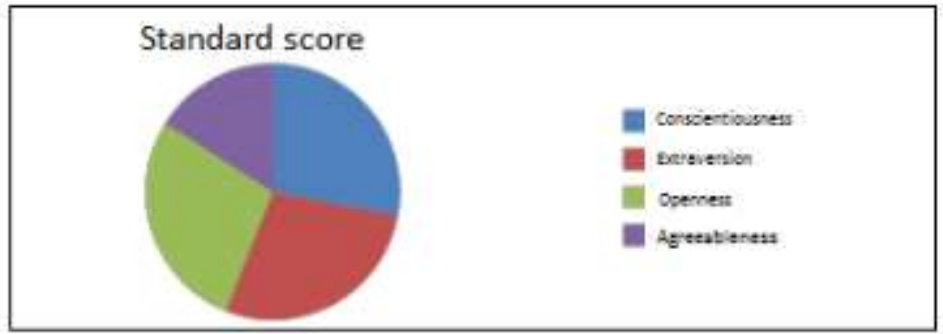

Fig. 10 Standard score P.Ł.

\section{III.6M.F (no 5) 4.0 points}

The conducted research has shown that the subject got high scores on the scales of extraversion, conscientiousness. The raw score was: CON-31, EX-35. The standard score CON-6, EX-8. On the scales of openness and agreeableness the subject received low scores, the raw scores: OP-25, AGR-20, the standard scores: OP-4, AGR-3. People characterized by a low level of openness tend to be conservative when it comes to their value system, but the level of openness itself may be modified by the environment and situations in which the subject participates. Low level of agreeableness is characteristic of the people who are critical, distanced and sceptical. Their individualism and need to be different mean that they almost always have an opinion on a given subject. They also think that every person has a right to have their own opinion and that a healthy dose of competition is crucial to every endeavour. The analysis of the aforementioned research shows that the subject presents character traits connected to extraversion and conscientiousness the subject is someone who is predominantly punctual and dependable in a workplace, tends to have fun, prefers to keep company and is optimistic and in a good mood.

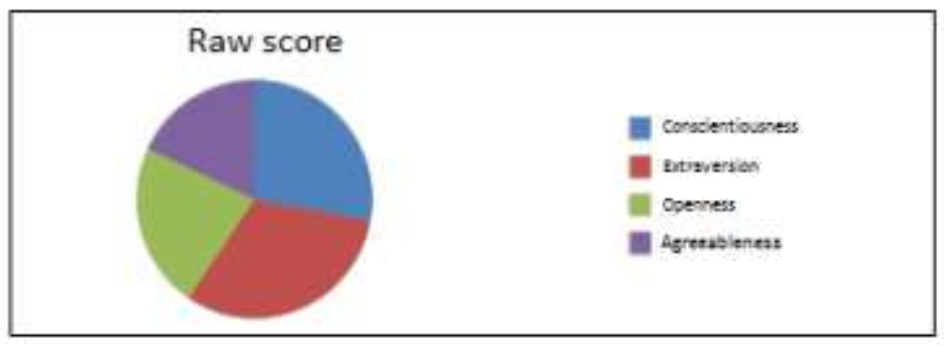

Fig. 11 Standard score M.F.

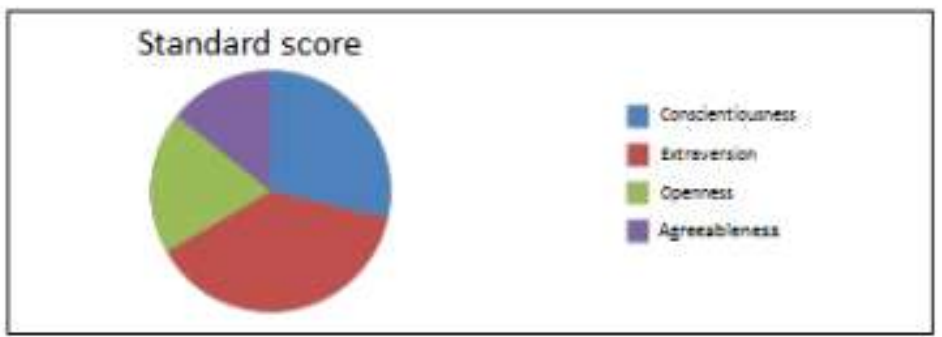

Fig. 12 Standard score M.F.

\section{Discussion}

Psychomotor agility of a person defines their ability to perform certain movements in the situations that require the entire body to move with the engagement of one's consciousness (Geblewiczowa 1965). The crucial aspect of every sport is the participation of human subjects who, in the reality of an arena, abide by the rules that pertain to every player when they make their decisions and take action bound by the strict array of possibilities. The characteristics and type of the game adjust the amount of effectiveness of the subject's participation in the game and the meaning of the rules that limit their freedom of action.

Martin (1988) states that the psychomotor agility combines many abilities: movement control, movement coordination, adaptation of physical movement. Every element is connected to the psychological and motoric capabilities of a player.

Chmura (1994) says that it is possible to observe only the aspects of individual's motor behavior that are determined by psychological traits. That leads to finding a connection between personality traits and cognitive, decision-making and executive processes. 
Specific forms of sport activity differ between each other when it comes to their stimulating value. That fact justifies the search for the influence of one's disposition on their preferences in this aspect. Sporting endeavours that include a ball are characterized by an extensive stimulating value. It can be assumed that people who specialize in wheelchair basketball and represent the highest world level are characterized by a high level of agility, quick reaction time, quick pace and swift reaction to the external changes (Strelau, Zawadzki 1993).

\section{Reference}

[1]. Chmura, J. (1994). Dynamika zmian reakcji fizjologicznych i sprawności psychomotorycznej pod wpływem wysiłków fizycznych. Katowice.

[2]. Costa P.T. ,McCrae R.R. (1992). Four ways five factors are basic. Personality and Individual Differences, 13(6), 653-665.

[3]. Geblewiczowa M. (1965). Szybkość reagowania, szybkość ruchów człowieka. Warszawa: INKF.

[4]. Krawczyk Z. (1978). Studia z filozofii i socjologii kultury fizycznej. Warszawa: Sport i Turystyka.

[5]. Martin D. (1988). Training im Kindels- und Jugendalter. Hofmann-Verlag Schorndorf. Studienbrief.

[6]. Naglak Z. (2001). Metodyka trenowania sportowca. Wrocław: Wydawnictwo AWF Wrocław.

[7]. Strelau J., Zawadzki B. (1993). The Formal Characteristic of Behavior-Temperament Inventory (FCB-IT): Theoretical assumptions and scale construction. European Journal of Personality, 7, 313-336.

[8]. Szarota P. 1995. Polska lista przymiotnikowa (PLP): Narzędzie do diagnozy pięciu wielkich czynników osobowości. Studia Psychologiczne, 33, 227-255.

[9]. Ważny Z. (1981). Współczesny system szkolenia w sporcie wyczynowym. Warszawa. 